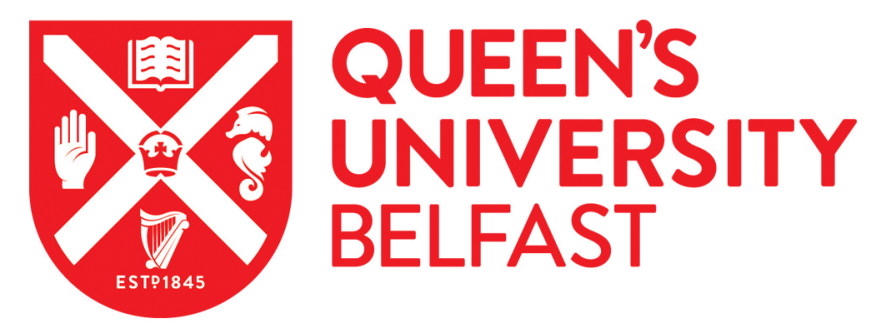

\title{
EDTA-enhanced phytoremediation of heavy metal contaminated soil and associated potential leaching risk
}

Wu, L. H., Luo, Y. M., Xing, X. R., \& Christie, P. (2004). EDTA-enhanced phytoremediation of heavy metal contaminated soil and associated potential leaching risk. Agriculture, Ecosystems and Environment, 102(3), 307318. https://doi.org/10.1016/j.agee.2003.09.002

Published in:

Agriculture, Ecosystems and Environment

Queen's University Belfast - Research Portal:

Link to publication record in Queen's University Belfast Research Portal

\section{General rights}

Copyright for the publications made accessible via the Queen's University Belfast Research Portal is retained by the author(s) and / or other copyright owners and it is a condition of accessing these publications that users recognise and abide by the legal requirements associated with these rights.

Take down policy

The Research Portal is Queen's institutional repository that provides access to Queen's research output. Every effort has been made to ensure that content in the Research Portal does not infringe any person's rights, or applicable UK laws. If you discover content in the Research Portal that you believe breaches copyright or violates any law, please contact openaccess@qub.ac.uk. 


\title{
EDTA-enhanced phytoremediation of heavy metal contaminated soil with Indian mustard and associated potential leaching risk
}

\author{
L.H. Wu ${ }^{\text {a,b,*}, \text { Y.M. Luo }}{ }^{\text {a }}$, X.R. Xing ${ }^{\mathrm{c}}$, P. Christie $^{\mathrm{d}}$ \\ a Soil and Environment Bioremediation Research Centre, Institute of Soil Science, Chinese Academy of Sciences, \\ PO Box 821, Nanjing 210008, PR China \\ ${ }^{\mathrm{b}}$ Laboratory of Terrestrial Ecological Processes, Institute of Applied Ecology, Chinese Academy of Sciences, Shenyang 110016, PR China \\ ${ }^{\mathrm{c}}$ Institute of Botany, Chinese Academy of Sciences, Beijing 100093, PR China \\ ${ }^{\mathrm{d}}$ Agricultural and Environmental Science Department, Queen's University Belfast, Newforge Lane, Belfast BT9 5PX, UK
}

Received 8 October 2002; received in revised form 26 August 2003; accepted 4 September 2003

\begin{abstract}
A glasshouse pot experiment and a laboratory leaching column experiment were conducted to study the EDTA enhancement of the mobility and phytoextraction of heavy metals and the potential for leaching of metals during the phytoextraction process.

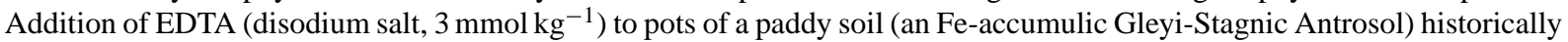
polluted with $\mathrm{Cu}$ and experimentally spiked with $\mathrm{Zn}, \mathrm{Pb}$ and $\mathrm{Cd}$ significantly enhanced the mobilities of soil $\mathrm{Cu}$ and $\mathrm{Pb}$ but not of $\mathrm{Zn}$ and $\mathrm{Cd}$. EDTA increased shoot $\mathrm{Cu}$ and $\mathrm{Pb}$ concentrations in Indian mustard (Brassica juncea) plants growing in the soil but the resulting offtakes were low and a sequence of at least 200 crops would be required to remediate the soil. Addition of oxalic, citric or malic acid to soil at the same rate $\left(3 \mathrm{mmol} \mathrm{kg}^{-1}\right)$ had virtually no effect on uptake of the metals by Indian mustard. EDTA addition led to elevated soil solution concentrations of TOC, $\mathrm{Cu}, \mathrm{Zn}, \mathrm{Pb}$ and $\mathrm{Cd}$ for about 1 month. Rainfall after EDTA application, as simulated by the column leaching experiment, increased the concentrations of $\mathrm{Cu}, \mathrm{Zn}, \mathrm{Pb}$ and $\mathrm{Cd}$ linearly in leachate with increasing EDTA dosage $\left(0-12 \mathrm{mmol} \mathrm{kg}^{-1}\right)$. EDTA addition also led to losses of soil macronutrients including $\mathrm{Fe}$. About $68 \%$ of the added EDTA tended to chelate soil $\mathrm{Cu}, \mathrm{Zn}, \mathrm{Pb}$ and $\mathrm{Cd}$ and the remaining $32 \%$ was chelated with and leached other ions. Total $\mathrm{Cu}, \mathrm{Zn}, \mathrm{Pb}$ and $\mathrm{Cd}$ losses were significantly correlated with EDTA dosage. The low shoot offtakes of $\mathrm{Pb}$ and $\mathrm{Cu}$ and the risk of groundwater pollution as EDTA remains active for several weeks make chelate-enhanced phytoremediation with Indian mustard unsuitable for this soil, especially during periods of high rainfall.
\end{abstract}

(C) 2003 Elsevier B.V. All rights reserved.

Keywords: Heavy metals; Phytoremediation; EDTA; Organic acids; Brassica juncea; Leaching risk

\section{Introduction}

Soils can be contaminated with heavy metals from various human activities including mining, smelting and metal treatment operations, vehicle emissions and

\footnotetext{
* Corresponding author. Tel.: +86-25-6881126; fax: +86-25-6881128.

E-mail addresses:1hwu0603@yahoo.com.cn, 1hwu@issas.ac.cn (L.H. Wu).
}

deposition or leakage of industrial wastes. Because of the potential toxicity and high persistence of heavy metals, the clean up of contaminated soils is one of the most difficult tasks for environmental engineering. A number of 'ex situ' and 'in situ' techniques have been developed to remove heavy metals from contaminated soils.

The technique of soil washing has been used to remove metals from the solid phase to a liquid matrix. Metal extraction can be achieved with organic 
or inorganic acids (Wasay et al., 1998, 2001; Davis et al., 1998). EDTA is the most effective and popular reagent because it is a strong, recoverable and relatively biostable chelating agent that has potential for soil remediation applications (Hong et al., 1999). The concentration and $\mathrm{pH}$ of a reagent influence the washing effect. When excessive EDTA is present, the amounts of cations extracted are usually pH-independent, but when EDTA is in short supply, the amounts of cations extracted show a complex behavior in relation to $\mathrm{pH}$ (Ghestem and Bermond, 1998). The mode of EDTA addition is also a significant factor controlling the behavior of metal leaching (Sun et al., 2001). In Ca-rich soil, the simultaneous dissolution of calcite was found to consume most of the available EDTA (Papassiopi et al., 1999), and adding $\mathrm{CaCl}_{2}$ or $\mathrm{KOH}$ was recommended (Heil et al., 1999), or using the calcium salt of EDTA instead of the common sodium salts (Theodoratos et al., 2000).

Phytoremediation of heavy metal contaminated soil is a developing technology that aims to extract or inactivate metals and it has attracted much attention because it is an environmentally friendly and relatively cheap technique (McGrath, 1998; McGrath et al., 2002). There are two basic strategies under development. The first is the use of hyperaccumulator plants that have the capacity to hyperaccumulate heavy metals, and the second is chemical chelate-enhanced phytoextraction (Salt et al., 1998). The major problem hindering plant remediation efficiency is that some of the metals are immobile in soil and their availability and phytoextraction rate are limited by solubility and diffusion to the root surface. Chemical enhancements have been used to overcome this problem (Blaylock et al., 1997; Huang et al., 1997; Ebbs and Kochian, 1997; Wu et al., 1999; Epstein et al., 1999), and the most promising application of this technology is for the remediation of $\mathrm{Pb}$-contaminated soils using Indian mustard (Brassica juncea (L.) Czern) in combination with EDTA (Blaylock, 2000). Despite the possible usefulness of this technology, some concerns have been expressed regarding the potential risk of leaching of metals to groundwater. EDTA significantly elevated the extractability of $\mathrm{Zn}$ and $\mathrm{Ni}$ in unpolluted and metal-amended soils and increased the mobility of $\mathrm{Zn}$ and $\mathrm{Ni}$ (Li and Shuman, 1996). EDTA mobilized metals rapidly, and subsequently their concentrations decreased slowly. High concentrations of heavy metals in the soil solution could pose an environmental risk in the form of groundwater contamination (Cooper et al., 1999; Lombi et al., 2001). Römkens et al. (2002) reported that EDTA, which has a high specific affinity for $\mathrm{Cd}$, enhanced metal solubility, but plant metal uptake did not increase accordingly and shoot and root biomass production was depressed. Furthermore, EDTA greatly reduced the number of microbivorous nematodes and enhanced metal leaching in a lysimeter study. Thus, potential environmental risk should be considered when chelate enhancement is used to improve phytoremediation efficiency.

Some studies have indicated that EDTA-metal complexes are resistant to microbial degradation. EDTA was found to be slowly biodegraded to $\mathrm{CO}_{2}$ in soil, with only $6.7 \%$ degraded after 4 weeks and a lower rate of degradation in the subsoil than in surface soil (Tiedje, 1975). Means et al. (1980) reported that the EDTA degradation rate was not rapid enough, even under optimal laboratory conditions, to preclude concern about its release to the environment. However, Belly et al. (1975) showed that $28 \%$ of the acetate-2-C and $30 \%$ of the ethylene position of ammonium ferric chelate of ${ }^{14} \mathrm{C}$-EDTA were recovered as ${ }^{14} \mathrm{CO}_{2}$ after 5 days. Little work has been done on the dynamics of EDTA degradation, and the extent of its limitation on mobilization of heavy metals is still unknown.

Experiments using soils artificially spiked with heavy metals may result in high performance of phytoextraction effects (Kumar et al., 1995) because of the high availability of heavy metals in artificially spiked soils. However, in sites with long-term heavy metal contamination, the phytoextraction effect on $\mathrm{Pb}$ was also extremely high (Huang et al., 1997). In the present paper, we report a glasshouse pot experiment and a laboratory leaching column experiment in which we studied a soil with long-term $\mathrm{Cu}$ contamination that was spiked with $\mathrm{Zn}, \mathrm{Cd}$ and $\mathrm{Pb}$ salts, Indian mustard (B. juncea) was used in the pot experiment. The aim was to investigate: (1) EDTA enhancement of mobility and phytoextraction of both historical and newly spiked heavy metals; (2) the progress of EDTA degradation and its effect on the mobility of the heavy metals; (3) the potential for leaching of heavy metals after EDTA addition to the soil with the consequent potential leaching risk during the phytoextraction process. 


\section{Materials and methods}

\subsection{Soil sampling and spiking with $\mathrm{Zn}, \mathrm{Cd}$ and $\mathrm{Pb}$}

Soil (an Fe-accumulic Gleyi-Stagnic Antrosol) was taken from the surface layer $(0-10 \mathrm{~cm})$ of a paddy field in Tai Lake Region, Jiangsu province, China, with a previous history of irrigation with $\mathrm{Cu}$-rich wastewater. The soil is a clay loam with a $\mathrm{pH}$ (in water) of 6.3. The soil was air-dried and spiked with 500, 500 and $50 \mathrm{mg} \mathrm{kg}^{-1}$ of $\mathrm{Zn}, \mathrm{Pb}$ and $\mathrm{Cd}$ by dissolving the nitrate salts in $150 \mathrm{ml}$ distilled water and mixing thoroughly into the soil to adjust the moisture content to about $40 \%$ of water holding capacity (WHC). Thorough mixing of the soil would have been much more difficult at higher soil moisture contents. The spiked soil was placed in a glasshouse for 1 month to allow it to equilibrate and to promote adsorption of the added metals. The soil was then air dried and sieved through a $2 \mathrm{~mm}$ nylon mesh for chemical analysis and use in the two experiments. Soil total $\left(\mathrm{HNO}_{3}-\mathrm{HClO}_{4}-\mathrm{HF}\right.$ digestion) $\mathrm{Cu}, \mathrm{Zn}, \mathrm{Pb}$ and $\mathrm{Cd}$ concentrations were 169 , 518, 492 and $45.7 \mathrm{mg} \mathrm{kg}^{-1}$, respectively.

\subsection{Pot experiment}

The treatments comprised the following amendments (all made at the rate of $3 \mathrm{mmol} \mathrm{kg}^{-1}$ soil on oven dry basis): (1) control with no amendment (CK); (2) EDTA disodium salt (EDTA); (3) oxalic acid (OA); (4) citric acid (CA); (5) malic acid (MA). Air-dried soil equivalent to $1.5 \mathrm{~kg}$ (oven dry basis) was placed in each plant pot $(15 \mathrm{~cm}$ top and $11 \mathrm{~cm}$ bottom diameters, and $12 \mathrm{~cm}$ high). $\mathrm{NH}_{4} \mathrm{NO}_{3}$ and $\mathrm{KH}_{2} \mathrm{PO}_{4}$ were applied as basal fertilizers at the rates of 0.43 and $0.33 \mathrm{~g} \mathrm{~kg}^{-1}$, respectively. Nine seeds of Indian mustard (B. juncea (L.) Czern, accession: Pl 426308, origin: Pakistan) were sown in each pot and thinned to three seedlings 13 days after sowing. All pots were adjusted daily by weight to $70 \%$ water holding capacity (WHC) with distilled water to maintain vigorous plant growth. There were three replicates of each treatment in a fully randomized design. Three additional replicates of the control and EDTA treatment were set up, each having one soil moisture suction sampler (Rhizon SMS: Rhizosphere Research Products, Wageningen, The Netherlands) installed in the center of each pot to permit sampling of the soil solution. EDTA and the other organic acid amendments were added to the pots 40 days after sowing and plants were harvested after 52 days. Soil solution samples were collected from the extra control and EDTA pots 6, 12, 29 and 52 days after the EDTA was applied to the soil. Each soil solution sample was separated into several aliquots for analysis of $\mathrm{pH}$, total organic carbon (TOC) content, and total and organic chelate combined $\mathrm{Cu}, \mathrm{Zn}, \mathrm{Pb}$ and $\mathrm{Cd}$ complexes concentrations by the methods of Holm et al. (1995). The aboveground parts of Indian mustard were washed with tap water and rinsed with distilled water, oven dried at $80^{\circ} \mathrm{C}$, ground and digested with $3: 2(\mathrm{v} / \mathrm{v}) \mathrm{ni}-$ tric/perchlolic acids. Fresh soil sub-samples were also collected to determine $1 \mathrm{M} \mathrm{NH}_{4} \mathrm{NO}_{3}$-extractable $\mathrm{Cu}$, $\mathrm{Zn}, \mathrm{Pb}$ and $\mathrm{Cd}$. Metal analysis was performed using a POEMS II (Thermo Jarrell Ash) inductively coupled plasma-atomic emission spectrometer (ICP-AES). Data are presented as the means of three replicates together with standard errors.

\subsection{Leaching column experiment}

A leaching column experiment was carried out to investigate the effects of the volume and $\mathrm{pH}$ of leaching water on soil heavy metals and other elements leaching from the 'arable' layer under different EDTA dosages in phytoremediation enhancement. The treatments are shown in Table 1 for clarity. A layer of fine sand (washed with $\mathrm{HCl}$, followed by tap water and then distilled water) and one sheet of $0.15 \mathrm{~mm}$ nylon

Table 1

Different treatments of leaching experiment ${ }^{\mathrm{a}}$

\begin{tabular}{|c|c|c|c|}
\hline Treatment & $\begin{array}{l}\text { EDTA } \\
\left(\mathrm{mmol} \mathrm{kg}^{-1}\right)\end{array}$ & $\begin{array}{l}\text { Water volume } \\
\text { (ml per event) }\end{array}$ & $\begin{array}{l}\text { Water } \\
\mathrm{pH}\end{array}$ \\
\hline 1. $\operatorname{EDTA}_{0}(20) 6$ & 0 & 20 & 6.0 \\
\hline 2. $\mathrm{EDTA}_{0}(40) 6$ & 0 & 40 & 6.0 \\
\hline 3. $\mathrm{EDTA}_{3}(20) 6$ & 3 & 20 & 6.0 \\
\hline 4. $\operatorname{EDTA}_{3}(40) 6$ & 3 & 40 & 6.0 \\
\hline 5. $\mathrm{EDTA}_{6}(20) 6$ & 6 & 20 & 6.0 \\
\hline 6. $\mathrm{EDTA}_{6}(40) 6$ & 6 & 40 & 6.0 \\
\hline 7. $\operatorname{EDTA}_{12}(20) 6$ & 12 & 20 & 6.0 \\
\hline 8. $\mathrm{EDTA}_{12}(20) 4.3$ & 12 & 20 & 4.3 \\
\hline 9. $\operatorname{EDTA}_{12}(20) 3$ & 12 & 20 & 3.0 \\
\hline 10. EDTA $_{12}(40) 6$ & 12 & 40 & 6.0 \\
\hline 11. $\operatorname{EDTA}_{12}(40) 4.3$ & 12 & 40 & 4.3 \\
\hline 12. $\mathrm{EDTA}_{12}(40) 3$ & 12 & 40 & 3.0 \\
\hline
\end{tabular}

${ }^{\text {a }}$ Each treatment was set up in triplicate. 
mesh were inserted into each PVC column $(3.3 \mathrm{~cm}$ i.d. and $25 \mathrm{~cm}$ in length). Air dried soil (historically contaminated with $\mathrm{Cu}$ and spiked with $\mathrm{Zn}, \mathrm{Pb}$ and $\mathrm{Cd}$ as described above) equivalent to $214 \mathrm{~g}$ (oven dry basis) was then added in small portions. The appropriate quantity of EDTA disodium salt was dissolved in $40 \mathrm{~g}$ distilled $\mathrm{H}_{2} \mathrm{O}$ and added to the soil surface in the columns to give a soil moisture content of about $40 \% \mathrm{WHC}$, and the following day the columns were placed in plastic saucers containing distilled water to maintain moisture content from the base. The columns were kept at room temperature 3 days before leaching. There were three replicates of each treatment. Twenty $\mathrm{ml}$ or $40 \mathrm{ml}$ of water at a specific $\mathrm{pH}$ value were added to the top of each column by syringe at a flow rate of $4 \mathrm{ml} \mathrm{h}^{-1}$. This comprised the first leaching event. The subsequent water application event of was made when no more leachate was produced. The soil hydraulic conductivity decreased with leaching water volume, and so the intervals of water addition were also lengthened. The aliquots of water (either 20 or $40 \mathrm{ml}$ ) were applied to the columns on 12 occasions over the course of the leaching experiment, which had a total duration of 48 days. The $\mathrm{pH}$ of the water applied to some of the columns was adjusted using a mixture of dilute nitric and sulfuric acids to include $\mathrm{pH}$ values of $\mathrm{pH} 4.3$ and 3.0 in order to simulate rainwater $\mathrm{pH}$ values found in the field. Each leachate was collected in a plastic bottle, weighed, and then separated into several portions for measurement of $\mathrm{pH}$ and determination of total organic carbon (TOC) and total $\mathrm{Cu}, \mathrm{Zn}, \mathrm{Pb}, \mathrm{Cd}, \mathrm{Fe}, \mathrm{Ca}$ and $\mathrm{Mg}$ concentrations. After the experiment, soil was removed from the columns, air dried, ground to $<0.25 \mathrm{~mm}$, and analyzed to investigate changes in total metal concentrations under different doses of EDTA, leaching water volumes and $\mathrm{pH}$ values. Metals were determined using a Thermo Jarrell Ash ICP-AES. TOC was determined using a Shimadzu 500A TOC Analyzer, and soil solution $\mathrm{pH}$ was measured using a pH meter. Data presented are means of three replicates together with standard errors.

\section{Results and discussion}

\subsection{Availabilities of soil heavy metals in pot experiment}

$\mathrm{NH}_{4} \mathrm{NO}_{3}$ is a weak extractant that extracts mainly the water-soluble and part of the exchangeable fraction of metals. The soil had been contaminated with $\mathrm{Cu}$ for more than 3 years before the pot experiment was conducted, hence the $\mathrm{NH}_{4} \mathrm{NO}_{3}$-extractable fraction was only $0.70 \mathrm{mg} \mathrm{kg}^{-1}$ in the absence of EDTA (Table 2). When $3 \mathrm{mmol} \mathrm{kg}^{-1}$ of EDTA was added, $\mathrm{NH}_{4} \mathrm{NO}_{3}$-extractable $\mathrm{Cu}$ increased to $52.7 \mathrm{mg} \mathrm{kg}^{-1}$, more than a 30 -fold increase over the control value. However, soil $\mathrm{NH}_{4} \mathrm{NO}_{3}$-extractable $\mathrm{Cu}$ did not increase when oxalic, citric or malic acid was applied at the same rate (Table 2). Lead is readily adsorbed by soil colloids, hence its mobility is always very low and this is considered to be the main factor restricting the phytoremediation of $\mathrm{Pb}$-contaminated soils. Thus, although the soil was newly spiked with $\mathrm{Pb}$ in this experiment, the $\mathrm{NH}_{4} \mathrm{NO}_{3}$ extractable $\mathrm{Pb}$ in non-EDTA-amended soil after plant growth was only $4.7 \mathrm{mg} \mathrm{kg}^{-1}$. EDTA addition significantly increased soil $\mathrm{NH}_{4} \mathrm{NO}_{3}$-extractable $\mathrm{Pb}$ to $26.6 \mathrm{mg} \mathrm{kg}^{-1}$, almost a six-fold increase compared with the unamended control. The three organic acids again had no effect on soil $\mathrm{NH}_{4} \mathrm{NO}_{3}-\mathrm{Pb}$. In contrast, $\mathrm{Zn}$ and $\mathrm{Cd}$ are highly mobile in the soil, and their $\mathrm{NH}_{4} \mathrm{NO}_{3}$-extractable

Table 2

Soil $\mathrm{NH}_{4} \mathrm{NO}_{3}$-extractable metals in the pot experiment $\left(\mathrm{mg} \mathrm{kg}^{-1}\right)^{\mathrm{a}, \mathrm{b}}$

\begin{tabular}{lcccc}
\hline Treatment $^{\mathrm{a}}$ & $\mathrm{Cu}\left(\mathrm{mg} \mathrm{kg}^{-1}\right)$ & $\mathrm{Zn}\left(\mathrm{mg} \mathrm{kg}^{-1}\right)$ & $\mathrm{Pb}\left(\mathrm{mg} \mathrm{kg}^{-1}\right)$ & $\left.\mathrm{Cd}_{(\mathrm{mg} \mathrm{kg}}^{-1}\right)$ \\
\hline CK & $0.70 \pm 0.10$ & $138 \pm 17$ & $4.66 \pm 0.69$ & $13.7 \pm 1.4$ \\
EDTA & $21.10 \pm 0.82$ & $174 \pm 8$ & $26.6 \pm 0.90$ & $15.6 \pm 0.2$ \\
OA & $0.64 \pm 0.04$ & $110 \pm 15$ & $3.86 \pm 0.97$ & $12.2 \pm 1.6$ \\
CA & $0.68 \pm 0.14$ & $100 \pm 18$ & $3.44 \pm 0.86$ & $11.0 \pm 1.3$ \\
MA & $0.68 \pm 0.10$ & $105 \pm 18$ & $4.05 \pm 0.43$ & $11.9 \pm 1.5$ \\
\hline
\end{tabular}

${ }^{\text {a }}$ CK: control with no amendment; EDTA: added EDTA disodium salt $3 \mathrm{mmol} \mathrm{kg}{ }^{-1}$ soil; OA: added oxalic acid $3 \mathrm{mmol} \mathrm{kg}^{-1}$ soil; CA: added citric acid $3 \mathrm{mmol} \mathrm{kg}{ }^{-1}$ soil; MA: added malic acid $3 \mathrm{mmol} \mathrm{kg}^{-1}$ soil.

${ }^{\mathrm{b}}$ Data are means of three observations \pm S.E. 
concentrations in the unamended control soil were 138 and $14 \mathrm{mg} \mathrm{kg}^{-1}$, representing 27 and $30 \%$ of soil total and spiked Zn and Cd. EDTA addition increased soil extractable $\mathrm{Zn}$ or $\mathrm{Cd}$ only slightly compared with its large influence on $\mathrm{Cu}$ and $\mathrm{Pb}$.

\subsection{Plant growth and heavy metal uptake}

There were no visible symptoms of heavy metal toxicity in Indian mustard during germination and growth. However, 2-4 days after EDTA addition into the soil there were numerous brown dots on the leaves, and the whole leaf became yellow and died slowly, indicating phytotoxicity of EDTA metals. There was no clear effect of the three organic acids on growth of Indian mustard. The aboveground yields were slightly lower in the EDTA treatment, but the differences among the five treatments were not significant (Table 3 ).

Table 3 also shows the $\mathrm{Cu}, \mathrm{Zn}, \mathrm{Pb}$ and $\mathrm{Cd}$ concentrations in Indian mustard shoots. Applied EDTA significantly increased both the mobility of soil $\mathrm{Cu}$ and the concentrations of $\mathrm{Cu}$ in the shoots of Indian mustard, whereas the three organic acids did not show this effect. EDTA also increased shoot $\mathrm{Pb}$ concentrations but, in common with the three organic acids, had little effect on shoot $\mathrm{Zn}$ and $\mathrm{Cd}$ concentrations.

Phytoextraction efficiency is related to both plant metal concentration and dry matter yield. Thus, the ideal plant species to remediate a contaminated site should be a high yielding crop that can both tolerate and accumulate the target contaminants. Indian mustard has been demonstrated to accumulate moderate levels of $\mathrm{Pb}, \mathrm{Zn}$ and $\mathrm{Cu}$ (Kumar et al., 1995; Ebbs and Kochian, 1997). When synthetic chelate was used, concentrations of $1.5 \%$ in the shoots of $B$. juncea were obtained from soils containing $600 \mathrm{mg} \mathrm{Pb} \mathrm{kg}^{-1}$ (Blaylock et al., 1997). The accession of Indian mustard used in the present experiment ( $\mathrm{Pl} \mathrm{426308)}$ is the same variety that was used by Ebbs and Kochian (1997) and it also showed good metal accumulation performance. Table 3 shows that shoot $\mathrm{Cu}$ uptake by plants growing in soil treated with EDTA was significantly higher than that of the unamended control, whereas the three organic acids had no effect on shoot $\mathrm{Cu}$ uptake. Lead uptake in the EDTA treatment was nearly three-fold higher than the control. Although shoot $\mathrm{Pb}$ uptake was also enhanced by addition by oxalic, citric and malic acids, the increases were smaller than those produced by EDTA. Despite the enhancement of $\mathrm{Pb}$ and $\mathrm{Cu}$ uptake by Indian mustard shoots, in the added EDTA treatment, uptakes of $\mathrm{Cu}, \mathrm{Zn}, \mathrm{Pb}$ and Cd were only $0.11,0.44,0.02,0.39 \%$, respectively, of the soil total $\mathrm{Cu}, \mathrm{Zn}, \mathrm{Pb}$ or $\mathrm{Cd}$. These offtakes of the metals would not be adequate for practical remediation of the paddy soil. To achieve soil cleanup of this contaminated soil, a sequence of 53, 205, 6088, or 255 crops would be required.

\subsection{Soil solution TOC dynamics and EDTA degradation}

Fig. 1a shows the TOC dynamics in the soil solution in the pot experiment. Six days after EDTA was applied the soil solution TOC in the EDTA treatment was $651 \mathrm{mgl}^{-1}, 746 \%$ of the control. Six days later the soil solution TOC had decreased by $45.3 \%$ to only $356 \mathrm{mg} \mathrm{l}^{-1}$ but was still higher than the control. Soil solution TOC decreased quickly with time; on the 29th day after EDTA application it was only $17.2 \%$ of the value on the 6th day, and there was no difference

Table 3

Plant shoot DM yields (g per pot), heavy metal concentrations and uptakes in the pot experiment ${ }^{\mathrm{a}}$

\begin{tabular}{|c|c|c|c|c|c|c|c|c|c|}
\hline \multirow[t]{2}{*}{ Treatment $^{\mathrm{b}}$} & \multirow[t]{2}{*}{ Shoot yield } & \multicolumn{4}{|c|}{ Heavy metal concentrations $\left(\mathrm{mg} \mathrm{kg}^{-1}\right)$} & \multicolumn{4}{|c|}{ Heavy metal uptakes (mg pot per $1.5 \mathrm{~kg}$ soil) } \\
\hline & & $\mathrm{Cu}$ & $\mathrm{Zn}$ & $\mathrm{Pb}$ & $\mathrm{Cd}$ & $\mathrm{Cu}$ & $\mathrm{Zn}$ & $\mathrm{Pb}$ & $\mathrm{Cd}$ \\
\hline $\mathrm{CK}$ & $7.84 \pm 2.38$ & $15.3 \pm 3.0$ & $460 \pm 63$ & $5.6 \pm 0.1$ & $37.1 \pm 1.2$ & $0.12 \pm 0.01$ & $3.68 \pm 1.59$ & $0.04 \pm 0.01$ & $0.29 \pm 0.10$ \\
\hline EDTA & $7.34 \pm 0.91$ & $39.8 \pm 8.7$ & $471 \pm 85$ & $15.8 \pm 6.2$ & $36.8 \pm 7.0$ & $0.29 \pm 0.06$ & $3.41 \pm 0.24$ & $0.12 \pm 0.05$ & $0.27 \pm 0.02$ \\
\hline $\mathrm{OA}$ & $8.51 \pm 3.83$ & $14.2 \pm 1.5$ & $553 \pm 35$ & $12.2 \pm 4.7$ & $41.5 \pm 0.8$ & $0.12 \pm 0.06$ & $4.61 \pm 1.85$ & $0.09 \pm 0.02$ & $0.44 \pm 0.06$ \\
\hline $\mathrm{CA}$ & $8.54 \pm 2.24$ & $13.7 \pm 3.2$ & $390 \pm 32$ & $12.2 \pm 5.1$ & $35.6 \pm 4.1$ & $0.12 \pm 0.06$ & $3.38 \pm 1.13$ & $0.10 \pm 0.02$ & $0.30 \pm 0.05$ \\
\hline MA & $8.39 \pm 1.68$ & $14.7 \pm 1.2$ & $626 \pm 51$ & $7.0 \pm 0.8$ & $46.3 \pm 5.4$ & $0.12 \pm 0.02$ & $5.30 \pm 1.38$ & $0.06 \pm 0.02$ & $0.40 \pm 0.12$ \\
\hline
\end{tabular}

${ }^{\text {a }}$ Data are means of three observations \pm S.E.

b Please see footnote "a" of Table 2 for details of each treatment. 


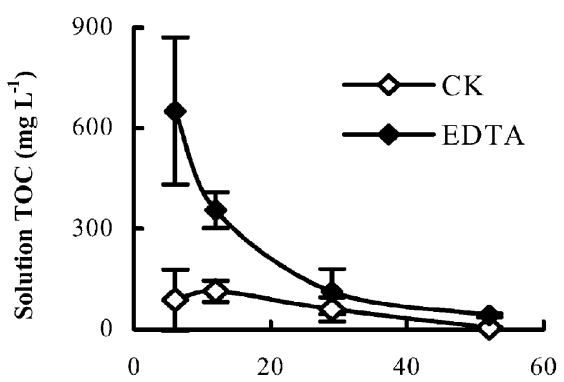

(a) Time after EDTA addition (days)

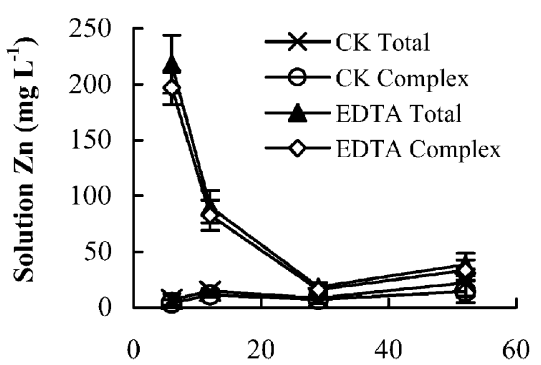

(c) Time after EDTA addition (days)

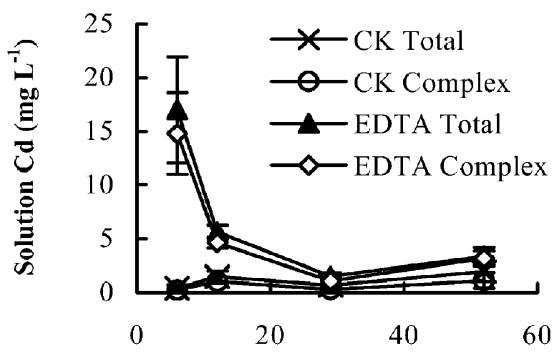

(e)

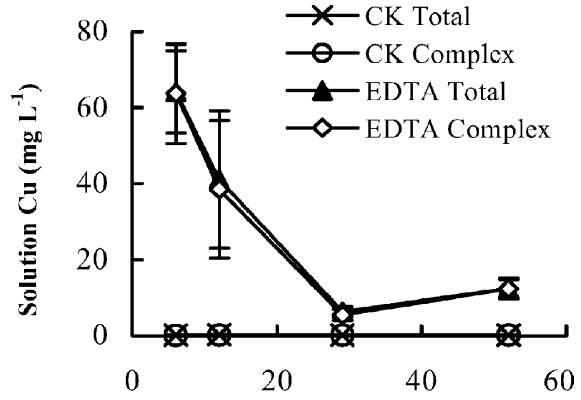

(b)

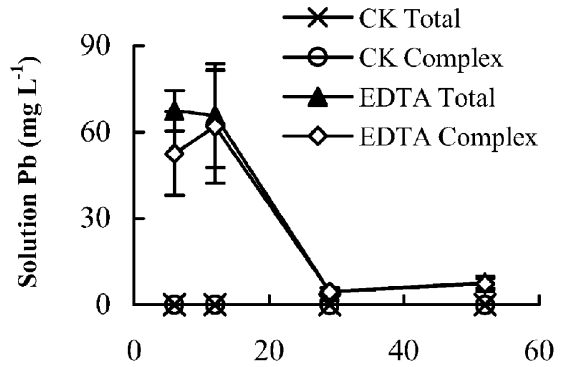

(d) Time after EDTA addition (days)

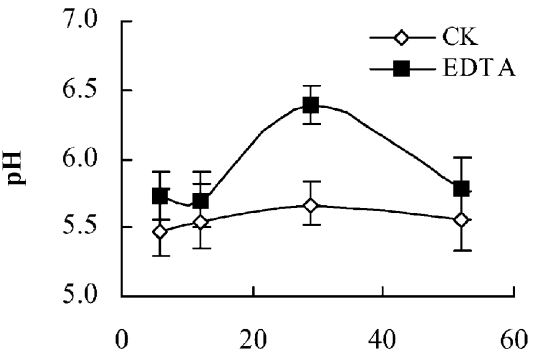

(f)

Time after EDTA addition (days)

Fig. 1. Soil solution (a) TOC, (b) $\mathrm{Cu}$, (c) $\mathrm{Zn}$, (d) $\mathrm{Pb}$, (e) $\mathrm{Cd}$ and (f) $\mathrm{pH}$ dynamics in the pot experiment; bars: \pm S.E. CK: control with no amendment; EDTA: added EDTA disodium salt $3 \mathrm{mmol} \mathrm{kg}^{-1}$; TOC: soil solution total organic carbon content collected by soil moisture suction sampler; $\mathrm{CK}$ total: total metal $(\mathrm{Cu}, \mathrm{Zn}, \mathrm{Pb}$ or $\mathrm{Cd})$ concentration in soil solution; $\mathrm{CK}$ complex: concentration of metal $(\mathrm{Cu}, \mathrm{Zn}, \mathrm{Pb}$ or $\mathrm{Cd}$ ) chelated by soil organic matter in the treatment of $\mathrm{CK}$; EDTA complex: concentration of metal $(\mathrm{Cu}, \mathrm{Zn}, \mathrm{Pb}$ or $\mathrm{Cd}) \mathrm{chelated}$ by EDTA and soil organic matter in the treatment of EDTA $\left(3 \mathrm{mmol} \mathrm{kg}{ }^{-1}\right)$.

between days 52 and 29 even though it remained higher than the control.

Soil solution $\mathrm{Cu}$ in the pot experiment was markedly enhanced by EDTA addition (Fig. 1b). On the 6th day the $\mathrm{Cu}$ concentration was $64.1 \mathrm{mg} \mathrm{l}^{-1}$ in the EDTA treatment but only $0.08 \mathrm{mgl}^{-1}$ in the control. On day 29 , soil solution $\mathrm{Cu}$ decreased to $6.25 \mathrm{mg}^{-1}$, but was still higher than the control. From days 29-52 the soil solution $\mathrm{Cu}$ concentration remained at a low level but was much higher than the control. The dynamics of soil solution $\mathrm{Zn}, \mathrm{Pb}$ and $\mathrm{Cd}$ concentrations were similar to those of $\mathrm{Cu}$ (Fig. 1c-e). The $\mathrm{Pb}$ concentration in the soil solution was also higher in the EDTA treatment than the control throughout the experiment, but after day 29 there were no differences in $\mathrm{Zn}$ and $\mathrm{Cd}$. These results may be attributed to the contamination of the soil with $\mathrm{Cu}$-rich wastewater more than 3 years before sampling. Thus a substantial proportion of soil $\mathrm{Cu}$ may 
have combined with immobile soil constituents over this time period and some of this $\mathrm{Cu}$ may have been re-mobilized by EDTA. The soil was spiked with $\mathrm{Zn}$ and $\mathrm{Cd} 1$ month before the experiment and their mobilities remained high. Lead would have been readily adsorbed by soil colloids and other soil components, and its activity was always very low, so that EDTA increased the activity of $\mathrm{Pb}$ much more than $\mathrm{Zn}$ or $\mathrm{Cd}$. This is considered to be the reason why EDTA can enhance $\mathrm{Pb}$ phytoremediation efficiency (Blaylock et al., 1997; Huang et al., 1997; Cooper et al., 1999). The organic chelate combined metal-complexes fraction is the portion chelated by soil organic matter and the added EDTA, and much of this can be considered to be mobile fraction. Fig. 1 shows that the heavy metals in the soil solution were mainly metal-complexes, especially when EDTA was used. This agrees with Lombi et al. (2001) who found that most of the heavy metals in soil pore waters were complexed by EDTA. Total amount and heavy metal-complexes were lower on the day 29 than on day 52, possibly because of an increase in soil solution $\mathrm{pH}$ resulting from soil organic matter and EDTA degradation and the appearance of a $\mathrm{CO}_{2}$ emission peak (Fig. 2f).

EDTA disappearance may be due to biodegradation, chemical degradation, soil sorption and evaporation (Means et al., 1980). EDTA may have chelated with soil $\mathrm{Cu}, \mathrm{Zn}, \mathrm{Pb}$ and $\mathrm{Cd}$ and then enhanced the mobility of soil heavy metals in the long term. This may be why soil solution total and non-labile $\mathrm{Cu}, \mathrm{Zn}, \mathrm{Pb}$ and $\mathrm{Cd}$ remained high while TOC decreased to a very low level. Disappearance of EDTA in our pot experiment was faster than reported by Tiedje (1975) but slower than that observed by Means et al. (1980). Differences in EDTA disappearance may be due, at least in part, to different experimental conditions and soil types.

\subsection{Effect of EDTA dosage on leaching of soil heavy metals}

In the leaching column experiment rainfall processes were simulated after EDTA was used as a chelate to enhance phytoremediation efficiency. Fig. 2a shows the leachate TOC concentration dynamics. In the treatment consisting of $20 \mathrm{ml}$ leaching aliquots of water, the leachate from the first leaching event from controls and columns treated with 3,6 and $12 \mathrm{mmol} \mathrm{kg}^{-1}$ leachate had TOC concentrations of 1131, 1870, 2540 and
$4603 \mathrm{mg} \mathrm{l}^{-1}$, showing increasing TOC with increasing EDTA dosage. Leachate TOC decreased quickly with leaching time and after the seventh leaching event (19 days from the start of the experiment), leachate TOC in EDTA treatments $0,3,6$ and $12 \mathrm{mmol} \mathrm{kg}^{-1}$ were only $199,340,515$ and $684 \mathrm{mg} \mathrm{l}^{-1}$.

Fig. 2 shows the $\mathrm{Cu}, \mathrm{Zn}, \mathrm{Pb}$ and $\mathrm{Cd}$ dynamics in the leachates. At the first event the $\mathrm{Cu}$ concentration in the control was only $0.57 \mathrm{mg}^{-1}$ and with the three increasing EDTA addition levels leachate $\mathrm{Cu}$ increased with values of 60.6, 106.0 and $222 \mathrm{mg} \mathrm{l}^{-1}$ (Fig. 2b). Thus, leachate $\mathrm{Cu}$ concentration increased by $100-400$ folds. Leachate $\mathrm{Cu}$ concentration decreased quickly with leaching time and at the seventh event there was no difference among the treatments, a similar trend to leachate TOC. Linear correlation analysis showed that between the first and seventh leaching events there was a strong relationship between leachate TOC and $\mathrm{Cu}$ concentration $(r=0.93, n=16, P<0.01)$. This indicates that soil $\mathrm{Cu}$ was mainly chelated by the EDTA and then moved out from the 'arable' layer to the deep layers of the soil profile. This agrees with the soil solution metal dynamics results obtained in the pot experiment in which the soil solution $\mathrm{Cu}$ was mainly combined (complexed) with EDTA and other soil organic chelates (Fig. 1). Concentrations of $\mathrm{Zn}$ (Fig. 2c), Pb (Fig. 2d) and Cd (Fig. 2e) in the column leachates showed trends similar to those of $\mathrm{Cu}$.

Fig. $2 \mathrm{f}$ shows that the leachate Fe concentration was very high when EDTA was added and increased with increasing EDTA dosage. Calcium and Mg concentrations were very high at the first leaching event and were much higher in the controls receiving no EDTA than in those to which EDTA was added (Fig. 2g and h). Spiking the soil with $\mathrm{Zn}, \mathrm{Pb}$ and $\mathrm{Cd}$ resulted in high concentrations of exchangeable (and therefore high availability of) $\mathrm{Ca}$ and $\mathrm{Mg}$ with consequent high concentrations in leachate. However, EDTA addition elevated soil $\mathrm{Cu}, \mathrm{Zn}, \mathrm{Pb}$ and $\mathrm{Cd}$ activities and decreased soil $\mathrm{Ca}$ and $\mathrm{Mg}$ mobility somewhat, and this resulted in low $\mathrm{Ca}$ and $\mathrm{Mg}$ in the leachate. Leachate $\mathrm{Ca}$ and $\mathrm{Mg}$ concentrations decreased quickly and at the second leaching event, the highest EDTA $\left(12 \mathrm{mmol} \mathrm{kg}^{-1}\right)$ treatment had the lowest $\mathrm{Ca}$ and $\mathrm{Mg}$ concentrations and there was no difference among the other three treatments. This indicates that soil $\mathrm{Ca}$ and $\mathrm{Mg}$ were very mobile and likely to be leached quickly. This may explain the rapid loss in soil hydraulic conductivity 


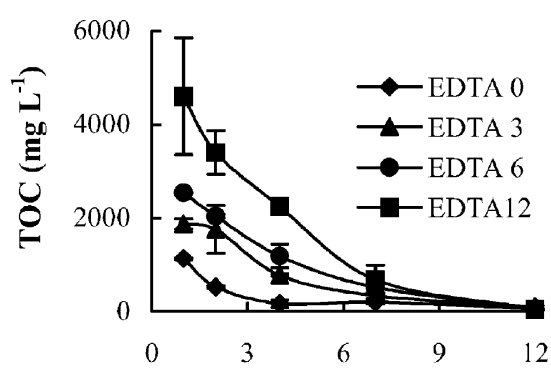

(a)
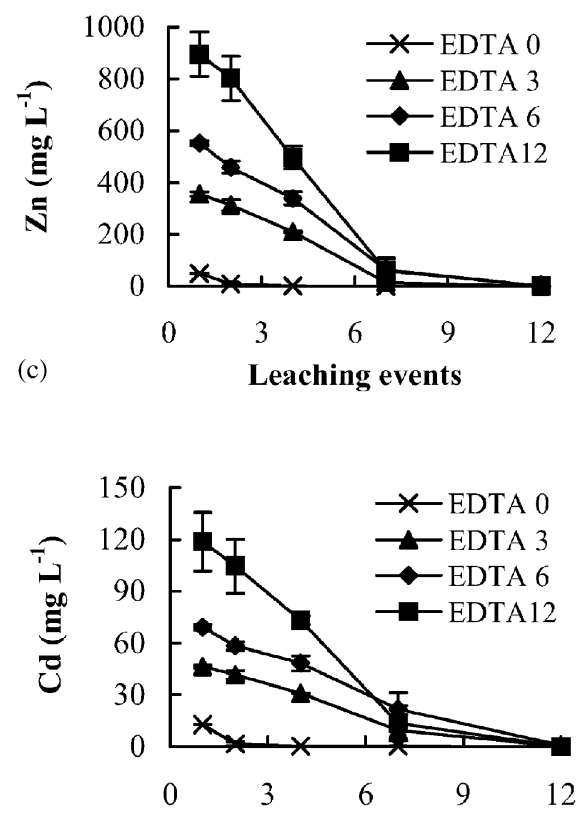

(e)

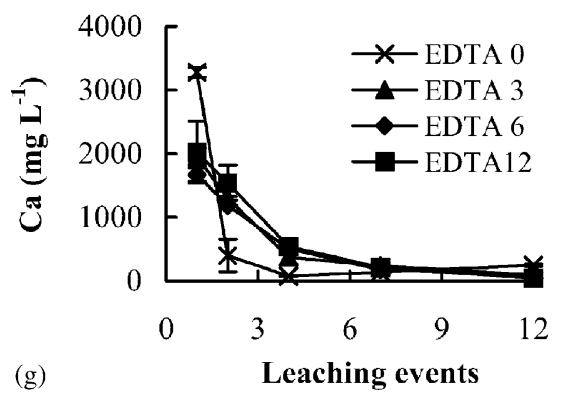

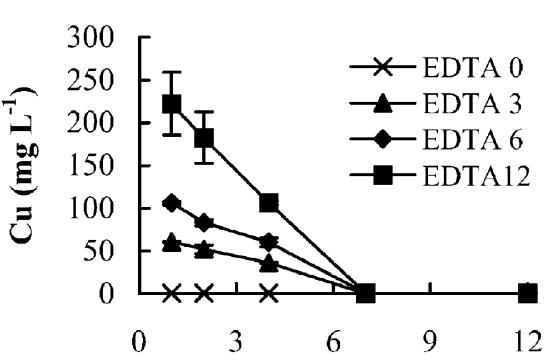

(b)
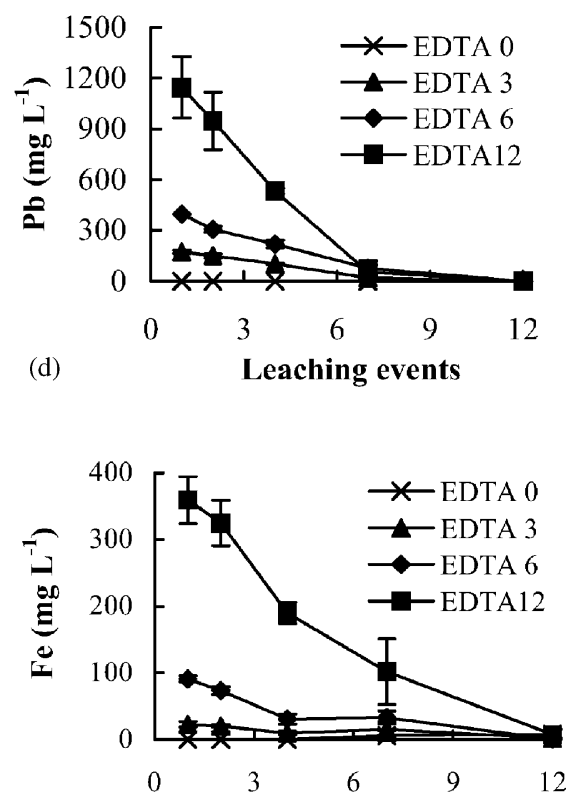

(f)

Leaching events

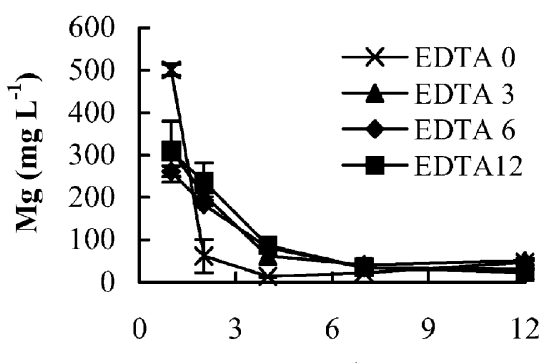

(h) Leaching events

Fig. 2. Effect of EDTA on leachate (a) TOC content and (b) $\mathrm{Cu}$, (c) $\mathrm{Zn}$, (d) $\mathrm{Pb}$, (e) $\mathrm{Cd}$, (f) $\mathrm{Fe}$, (g) $\mathrm{Ca}$ and (h) $\mathrm{Mg}$ concentrations in the column leaching experiment; bars: \pm S.E. 
reported by Sun et al. (2001). Besides the leaching of $\mathrm{Cu}, \mathrm{Zn}, \mathrm{Pb}$ and $\mathrm{Cd}$, EDTA addition may also have led to losses of soil macronutrients including $\mathrm{Fe}, \mathrm{Ca}$ and $\mathrm{Mg}$ (Wasay et al., 1998). Our results did not agree with those of Wasay et al. (1998), perhaps because the soluble and the easily exchangeable fractions of soil $\mathrm{Ca}$ and $\mathrm{Mg}$ had already been leached from our paddy soil by long-term irrigation in the field.

\subsection{Effects of leaching water volume and $\mathrm{pH}$ on movement of heavy metals}

When EDTA was added to the soil at the rate of $3 \mathrm{mmol} \mathrm{kg}{ }^{-1}$, the soil total organic carbon concentration was very high, mainly due to the EDTA. Thus, at the first leaching event the leachate TOC concentration was very high. Leachate TOC was lower in columns to which $40 \mathrm{ml}$ of water were applied at each leaching event compared with $20 \mathrm{ml}$ (Fig. 3). Leachate TOC decreased with leaching time, but leachate TOC concentration was still different between the two leaching water aliquot treatments. By the seventh event there was little soluble $\mathrm{C}$ remaining in the soil, consequently there was no difference between the two treatments. Leachate $\mathrm{Cu}$ contents again showed similar dynamics to TOC. At the first leaching event the $\mathrm{Cu}$ ions were readily desorbed by EDTA so that there was

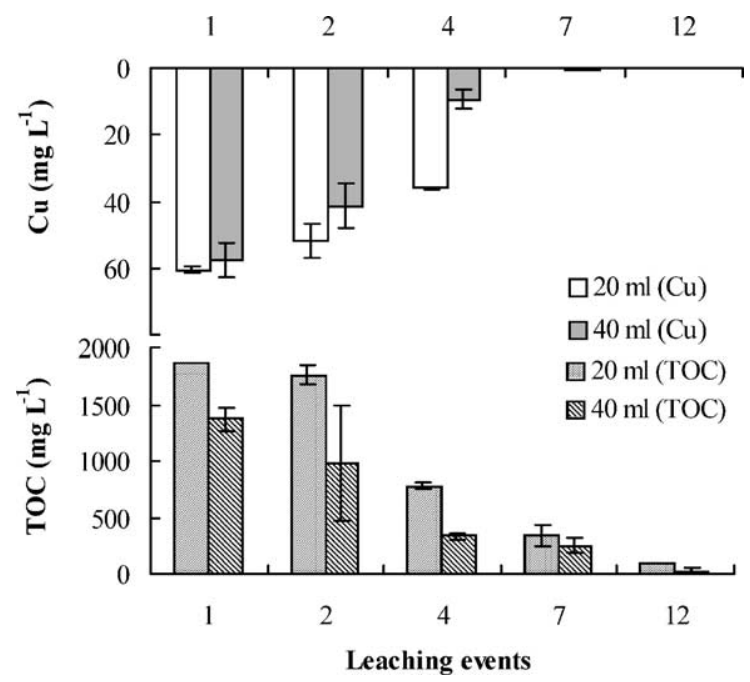

Fig. 3. Effect of leaching water volume on leachate TOC content and $\mathrm{Cu}$ concentration in the column leaching experiment. The data are from consecutive leaching events spread over a $48 \mathrm{~h}$ period; bars: \pm S.E. no difference between the two leaching water volume treatments (Fig. 3). Leachate $\mathrm{Cu}$ decreased with the increasing leaching time and the difference between the two leaching water volume treatments widened until at the fourth leaching event the two treatments were different. This may have been due to decreasing soil EDTA concentration as leaching proceeded over time. On the other hand, soil $\mathrm{Cu}$ adsorbed on soil colloids may have become more resistant to exchange and therefore less soluble. EDTA additions of 6 and $12 \mathrm{mmol} \mathrm{kg}^{-1}$ showed similar effects on leachate $\mathrm{Cu}$ concentrations (decreasing trends: data not shown). The effects of leaching water volume on leachate $\mathrm{Zn}$, $\mathrm{Pb}$ and $\mathrm{Cd}$ dynamics were similar to those on $\mathrm{Cu}$ dynamics (data not shown).

There was no significant difference among the three rainwater $\mathrm{pH}$ values on leachate concentrations of heavy metals or macronutrients in the short time frame of our experiment, perhaps reflecting the soil's high buffering capacity to changes in $\mathrm{pH}$ and indicating that rainfall $\mathrm{pH}$ may not be an important factor affecting leaching of heavy metals (data not shown). However, under field conditions rainfall $\mathrm{pH}$ may be more important in the long term.

\subsection{Amounts of soil macronutrients and heavy metals leached}

The amounts of $\mathrm{Fe}, \mathrm{Ca}$ and $\mathrm{Mg}$ leached are shown in Table 4. Loss of Fe increased markedly with increasing EDTA dosage. Calcium and $\mathrm{Mg}$ were leached at the

Table 4

Amounts of soil $\mathrm{Fe}, \mathrm{Ca}$ and lost after leaching in columns ${ }^{\mathrm{a}}$

\begin{tabular}{cclc}
\hline $\begin{array}{l}\text { Treatment } \\
\text { number }\end{array}$ & $\mathrm{Fe}\left(\mathrm{mg} \mathrm{kg}^{-1}\right)$ & $\mathrm{Ca}\left(\mathrm{mg} \mathrm{kg}^{-1}\right)$ & $\mathrm{Mg}\left(\mathrm{mg} \mathrm{kg}^{-1}\right)$ \\
\hline 1 & $3.37 \pm 3.66$ & $531 \pm 5$ & $84.2 \pm 0.8$ \\
2 & $7.43 \pm 0.24$ & $617 \pm 28$ & $98.4 \pm 5.7$ \\
3 & $12.6 \pm 1.1$ & $576 \pm 37$ & $101 \pm 7$ \\
4 & $12.1 \pm 1.2$ & $638 \pm 36$ & $119 \pm 2$ \\
5 & $37.0 \pm 2.3$ & $565 \pm 32$ & $96.1 \pm 2$ \\
6 & $41.2 \pm 1.7$ & $625 \pm 8$ & $130 \pm 2$ \\
7 & $163 \pm 9$ & $626 \pm 21$ & $102 \pm 1$ \\
8 & $178 \pm 9$ & $661 \pm 14$ & $111 \pm 1$ \\
9 & $169 \pm 4$ & $624 \pm 9$ & $108 \pm 11$ \\
10 & $189 \pm 14$ & $685 \pm 31$ & $122 \pm 1$ \\
11 & $155 \pm 32$ & $610 \pm 61$ & $104 \pm 23$ \\
12 & $147 \pm 4$ & $704 \pm 30$ & $114 \pm 4$ \\
\hline
\end{tabular}

${ }^{a}$ Data are means of three observations \pm S.E.

${ }^{\mathrm{b}}$ Please see Table 1 for details of each treatment number. 
Table 5

Soil total heavy metal concentrations after leaching in columns $\left(\mathrm{mg} \mathrm{kg}^{-1}\right)^{\mathrm{a}}$

\begin{tabular}{|c|c|c|c|c|c|c|c|c|}
\hline \multirow{2}{*}{$\begin{array}{l}\text { Treatment } \\
\text { number }^{b}\end{array}$} & \multicolumn{2}{|l|}{$\mathrm{Cu}$} & \multicolumn{2}{|l|}{$\mathrm{Zn}$} & \multicolumn{2}{|l|}{$\mathrm{Pb}$} & \multicolumn{2}{|l|}{$\mathrm{Cd}$} \\
\hline & Total & Lost (\%) & Total & Lost $(\%)$ & Total & Lost (\%) & Total & Lost $(\%)$ \\
\hline 1 & $167 \pm 5$ & 1.1 & $496 \pm 13$ & 4.2 & $459 \pm 2$ & 6.6 & $45.4 \pm 0.4$ & 0.7 \\
\hline 2 & $158 \pm 3$ & 6.4 & $477 \pm 10$ & 8.1 & $458 \pm 7$ & 6.8 & $45.0 \pm 1.0$ & 1.5 \\
\hline 3 & $150 \pm 1$ & 11.2 & $377 \pm 1$ & 27.2 & $420 \pm 4$ & 14.6 & $31.0 \pm 0.8$ & 32.2 \\
\hline 4 & $143 \pm 1$ & 15.6 & $366 \pm 5$ & 29.4 & $415 \pm 4$ & 15.6 & $30.4 \pm 0.3$ & 33.6 \\
\hline 5 & $132 \pm 1$ & 22.1 & $285 \pm 4$ & 44.9 & $347 \pm 7$ & 29.4 & $19.8 \pm 0.5$ & 56.7 \\
\hline 6 & $130 \pm 2$ & 23.1 & $276 \pm 6$ & 46.7 & $340 \pm 9$ & 30.8 & $18.7 \pm 0.4$ & 59.0 \\
\hline 7 & $105 \pm 2$ & 37.7 & $128 \pm 2$ & 75.2 & $171 \pm 6$ & 65.3 & $7.7 \pm 0.3$ & 83.1 \\
\hline 8 & $106 \pm 1$ & 37.5 & $113 \pm 1$ & 78.1 & $158 \pm 2$ & 67.9 & $7.2 \pm 0.1$ & 84.2 \\
\hline 9 & $104 \pm 1$ & 38.6 & $122 \pm 3$ & 76.5 & $166 \pm 3$ & 66.3 & $6.8 \pm 0.3$ & 85.1 \\
\hline 10 & $106 \pm 1$ & 37.5 & $116 \pm 1$ & 77.7 & $156 \pm 3$ & 68.2 & $6.9 \pm 0.2$ & 84.9 \\
\hline 11 & $103 \pm 2$ & 39.0 & $130 \pm 4$ & 74.9 & $173 \pm 11$ & 64.9 & $6.6 \pm 0.2$ & 85.5 \\
\hline 12 & $99 \pm 2$ & 41.1 & $115 \pm 7$ & 77.8 & $155 \pm 5$ & 68.5 & $5.9 \pm 0.2$ & 87.0 \\
\hline
\end{tabular}

${ }^{\text {a }}$ Data are means of three observations \pm S.E.

${ }^{\mathrm{b}}$ Please see Table 1 for details of each treatment number.

early stages and there were no differences among the treatments in losses of $\mathrm{Ca}$ and $\mathrm{Mg}$ (Table 4).

Soils were recovered from the columns at the end of the experiment and dried for determination of total $\mathrm{Cu}, \mathrm{Zn}, \mathrm{Pb}$ and $\mathrm{Cd}$ and calculation of the percentage of metal losses (Table 5). When either 20 or $40 \mathrm{ml}$ were added on each occasion with a total of 12 leaching events, only $1.1-6.4 \%$ of total $\mathrm{Cu}$ was lost. When EDTA was added to soil at the rates of 3, 6 or $12 \mathrm{mmol} \mathrm{kg}^{-1}$, the losses were 11.2-15.6, 22.1-23.1 and $37.5-41.1 \%$ of total $\mathrm{Cu}$. There was no significant effect of leaching volume or $\mathrm{pH}$ on $\mathrm{Cu}$ loss. Losses of $\mathrm{Zn}, \mathrm{Pb}$ and $\mathrm{Cd}$ were similar to those of $\mathrm{Cu}$.

Linear regression analysis revealed that $\mathrm{Cu}, \mathrm{Zn}, \mathrm{Pb}$ and Cd losses were closely related to EDTA according to the following equations:

$$
\begin{aligned}
& \text { Cu loss }\left(\mathrm{mg} \mathrm{kg}^{-1}\right) \\
& \quad=5.17 \times \text { EDTA }\left(\mathrm{mmol} \mathrm{kg}^{-1}\right)+6.86, \\
& r=0.97, n=12, P<0.001 ; \\
& \mathrm{Zn} \text { loss }\left(\mathrm{mg} \mathrm{kg}^{-1}\right) \\
& \quad=29.4 \times \text { EDTA }\left(\mathrm{mmol} \mathrm{kg}^{-1}\right)+47.2, \\
& r=0.99, n=12, P<0.001 ; \\
& \mathrm{Pb} \text { loss }\left(\mathrm{mg} \mathrm{kg}^{-1}\right) \\
& \quad=26.0 \times \text { EDTA }\left(\mathrm{mmol} \mathrm{kg}^{-1}\right)+12.0, \\
& r=0.99, n=12, P<0.001 ;
\end{aligned}
$$

$$
\begin{aligned}
& \text { Cd loss }\left(\mathrm{mg} \mathrm{kg}^{-1}\right) \\
& =2.96 \times \operatorname{EDTA}\left(\mathrm{mmol} \mathrm{kg}^{-1}\right)+4.19, \\
& r=0.98, n=12, P<0.001
\end{aligned}
$$

If the amounts of $\mathrm{Cu}, \mathrm{Zn}, \mathrm{Pb}$ and $\mathrm{Cd}$ lost are expressed in mmol kg-1, then the molar ratio of EDTAto-combined metal losses was 0.68 . Thus, about $2 / 3$ of the added EDTA was used to chelate soil $\mathrm{Cu}, \mathrm{Zn}, \mathrm{Pb}$ and $\mathrm{Cd}$ and moved out to the $0-20 \mathrm{~cm}$ 'arable' layer. The remaining $1 / 3$ of added EDTA chelated soil Fe, $\mathrm{Ca}, \mathrm{Mg}$ and other ions.

During phytoremediation enhancement procedures, EDTA solution is usually applied when adequate plant biomass has accumulated, and plant shoots are often harvested about 1 week later (Blaylock et al., 1997; Huang et al., 1997). When EDTA is applied, soil contaminants are mobilized significantly, and will be maintained at high concentrations in the soil for a long time. Thus, before EDTA is degraded to a low concentration, by which time its effect on the mobility of soil contaminants will be negligible, the side effects of EDTA enhancement in phytoremediation should give cause for concern. In a lysimeter study, Römkens et al. (2002) added 0.01 M EDTA twice within 1 week and this resulted in high concentrations of $\mathrm{Cu}$ and $\mathrm{Cd}$ in leachate. In field trials $0.5-2.5 \mathrm{~g}$ $\left(1.3-6.7 \mathrm{mmol} \mathrm{kg}^{-1}\right)$ of EDTA has been used as a chelate in phytoremediation (Huang et al., 1997; Blaylock et al., 1997; Ebbs and Kochian, 1998). Thus, 
0.01 M EDTA was a very high dosage, especially for a sandy soil, this may explain the high concentrations of $\mathrm{Cd}$ and $\mathrm{Cu}$ found in leachate.

Leaching will occur once the soil is saturated. The soil used in our experiment was a clay-loam with a water holding capacity (WHC) of $47.9 \%$. If soil water content was $60 \%$ of WHC, there would still be $40 \%$ of WHC required to reach saturation. If we assume that the arable layer is $20 \mathrm{~cm}$ deep, then rainfall over $38 \mathrm{~mm}$ will saturate the soil (starting at $60 \%$ WHC) and then leach the EDTA-mobilized heavy metals to groundwater. Thus, heavy rainfall will produce a high risk of heavy metal. In Tai Lake region in east China, during the heavy rainfall season chelate-assisted phytoremediation would not be an appropriate technique because results from the pot experiment indicate that EDTA application would markedly enhance soil $\mathrm{Cu}$, $\mathrm{Zn}, \mathrm{Pb}$ and $\mathrm{Cd}$ mobility for a period of about 1 month. Where rainfall or irrigation is heavy enough to saturate the soil, and where leaching water cannot be collected, chelate-based phytoremediation behavior should be carefully managed to avoid the risk of heavy metal contamination of groundwater.

\subsection{Phytoremediation potential of the soil using EDTA enhancement}

EDTA (disodium salt, $3 \mathrm{mmol} \mathrm{kg}^{-1}$ ) added to a heavy paddy soil significantly enhanced the mobility of soil $\mathrm{Cu}$ (the historical contaminant) and $\mathrm{Pb}$ (one of the newly introduced contaminants but one easily precipitated) but had no effect on $\mathrm{Zn}$ and $\mathrm{Cd}$, which were both newly introduced pollutants. Concentrations of $\mathrm{Cu}$ and $\mathrm{Pb}$ in shoots of Indian mustard were also increased by EDTA addition. Despite the above effects, uptakes of $\mathrm{Cu}, \mathrm{Zn}, \mathrm{Pb}$ and $\mathrm{Cd}$ by the plants were only $0.11,0.44,0.02$ and $0.39 \%$, respectively, of the soil total $\mathrm{Cu}, \mathrm{Zn}, \mathrm{Pb}$ and $\mathrm{Cd}$. To achieve cleanup of this contaminated soil to normal $\mathrm{Cu}, \mathrm{Zn}, \mathrm{Pb}$ and Cd concentrations, a sequence of 753, 205, 6088 or 255 crops of Indian mustard would be required. Thus, chelate-enhanced phytoextraction might not be an adequate technique for this soil. Soil solution TOC and heavy metal results from the pot experiment show that EDTA existed for about 1 month and remained active to mobilize soil $\mathrm{Cu}, \mathrm{Zn}, \mathrm{Pb}$ and $\mathrm{Cd}$. Furthermore, rainfall processes after EDTA application would increase the concentrations of $\mathrm{Cu}, \mathrm{Zn}, \mathrm{Pb}$ and Cd leaching through the soil, especially at the early stages of leaching. About $68 \%$ of the added EDTA tended to chelate soil $\mathrm{Cu}, \mathrm{Zn}, \mathrm{Pb}$ and $\mathrm{Cd}$ and the remaining $32.2 \%$ would have combined with and leached other ions. The total $\mathrm{Cu}, \mathrm{Zn}, \mathrm{Pb}$ and $\mathrm{Cd}$ losses were also correlated with the EDTA dosage. In conclusion, EDTA-enhanced phytoextraction would not remove adequate quantities of heavy metals from this soil in Tai Lake region and would pose a potentially high risk for contamination of groundwater, especially during the season of high rainfall, and would therefore not be an appropriate remediation technique for this soil, even for $\mathrm{Pb}$ or $\mathrm{Cu}$.

\section{Acknowledgements}

The authors are grateful for grant-aided support from the Natural Science Foundation of China (nos. 40001013 and 40125005), the Major State Basic Research and Development Program of PR China (2002CB410809/10), and the Natural Science Foundation of Jiangsu Province (BK2001194).

\section{References}

Belly, R.T., Lauff, J.J., Goodhue, C.T., 1975. Degradation of ethylenediaminetetraacetic acid by microbial populations from an aerated lagoon. Appl. Microbiol. 29, 787-794.

Blaylock, M.J., 2000. Field demonstration of phytoremediation of lead contaminated soils. In: Terry, N., Banuelos, G. (Eds.), Phytoremediation of Contaminated Soil and Water. Lewis Publishers, Boca Raton, FL, pp. 1-12.

Blaylock, M.J., Salt, D.E., Dushenkov, S., Zakharova, O., Gussman, C., Kapulnik, Y., Ensley, B.D., Raskin, I., 1997. Enhanced accumulation of $\mathrm{Pb}$ in Indian mustard by soil-applied chelating agents. Environ. Sci. Technol. 31, 860-865.

Cooper, E.M., Sims, J.T., Cunningham, S.D., Huang, J.W., Berti, W.R., 1999. Chelate-assisted phytoextraction of lead from contaminated soils. J. Environ. Qual. 28, 1709-1719.

Davis, A.P., Matange, D., Shokouhian, M., 1998. Washing of cadmium(II) from a contaminated soil column. J. Soil Contam. 7, 371-393.

Ebbs, S.D., Kochian, L.V., 1997. Toxicity of zinc and copper to Brassica species: implications for phytoremediation. J. Environ. Qual. 26, 776-781.

Ebbs, S.D., Kochian, L.V., 1998. Phytoextraction of zinc by oat (Avena sativa), barley (Hordeum vulgare), and Indian mustard (Brassica juncea). Environ. Sci. Technol. 32, 802-806.

Epstein, A.L., Gussman, C.D., Blaylock, M.J., Yermiyahu, U., Huang, J.W., Kapulnik, Y., Orser, C.S., 1999. EDTA 
and $\mathrm{Pb}$-EDTA accumulation in Brassica juncea grown in Pb-amended soil. Plant and Soil 208, 87-94.

Ghestem, J.P., Bermond, A., 1998. EDTA extractability of trace metals in polluted soils: a chemical-physical study. Environ. Technol. 19, 409-416.

Heil, D.M., Samani, Z., Hanson, A.T., Rudd, B., 1999. Remediation of lead contaminated soil by EDTA. I. Batch and column studies. Water Air Soil Pollut. 113, 77-95.

Holm, P.E., Christensen, T.H., Tjell, J.C., McGrath, S.P., 1995. Speciation of cadmium and zinc with application to soil solutions. J. Environ. Qual. 24, 183-190.

Hong, P.K.A., Li, C., Banerji, S.K., Regmi, T., 1999. Extraction, recovery, and biostability of EDTA for remediation of heavy metal-contaminated soil. J. Soil Contam. 8, 81-103.

Huang, J.W., Chen, J.J., Berti, W.R., Cunningham, S.D., 1997. Phytoremediation of lead-contaminated soils: role of synthetic chelates in lead phytoextraction. Environ. Sci. Technol. 31, 800-805.

Kumar, P.B.A.N., Dushenkov, V., Motto, H., Raskin, I., 1995. Phytoextraction: the use of plants to remove heavy metals from soils. Environ. Sci. Technol. 29, 1232-1238.

Li, Z.B., Shuman, L.M., 1996. Extractability of zinc, cadmium, and nickel in soils amended with EDTA. Soil Sci. 161, 226-232.

Lombi, E., Zhao, F.J., Dunham, S.J., McGrath, S.P., 2001. Phytoremediation of heavy metal-contaminated soils: natural hyperaccumulation versus chemically enhanced phytoextraction. J. Environ. Qual. 30, 1919-1926.

McGrath, S.P., 1998. Phytoextraction for soil remediation. In: Brooks, R.R. (Ed.), Plants that Hyperaccumulate Heavy Metals. CAB International, Wallingford, UK, pp. 261-287.

McGrath, S.P., Zhao, F.J., Lombi, E., 2002. Phytoremediation of metals, metalloids, and radionuclides. Adv. Agron. 75, 1-56.
Means, J.L., Kucak, T., Crerar, D.A., 1980. Relative degradation rates of NTA, EDTA and DTPA and environmental applications. Environ. Pollut. (Ser. B) 1, 45-60.

Papassiopi, N., Tambouris, S., Kontopoulos, A., 1999. Removal of heavy metals from calcareous contaminated soils by EDTA leaching. Water Air Soil Pollut. 109, 1-15.

Römkens, P., Bouwman, L., Japenga, J., Draaisma, C., 2002. Potentials and drawbacks of chelate-enhanced phytoremediation of soils. Environ. Pollut. 116, 109-121.

Salt, D.E., Smith, R.D., Raskin, I., 1998. Phytoremediation. Ann. Rev. Plant Physiol. Plant Mol. Biol. 49, 643-668.

Sun, B., Zhao, F.J., Lombi, E., McGrath, S.P., 2001. Leaching of heavy metals from contaminated soils using EDTA. Environ. Pollut. 113, 111-120.

Theodoratos, P., Papassiopi, N., Georgoudis, T., Kontopoulos, A., 2000. Selective removal of lead from calcareous polluted soils using the Ca-EDTA salt. Water Air Soil Pollut. 122, 351368.

Tiedje, J.M., 1975. Microbial degradation of ethylenediaminetetraacetate in soils and sediments. Appl. Microbiol. 30, 327329.

Wasay, S.A., Barrington, S.F., Tokunaga, S., 1998. Remediation of soils polluted by heavy metals using salts of organic acids and chelating agents. Environ. Technol. 19, 369-379.

Wasay, S., Barrington, S.E., Tokunaga, S., 2001. Organic acids for the in situ remediation of soils polluted by heavy metals: soil flushing in columns. Water Air Soil Pollut. 127, 301-314.

Wu, J., Hsu, F.C., Cunningham, S.D., 1999. Chelate-assisted $\mathrm{Pb}$ phytoextraction: $\mathrm{Pb}$ availability, uptake, and translocation constraints. Environ. Sci. Technol. 33, 1898-1904. 